\title{
Kepemimpinan Transformasional Suatu Alternatif Pembelajaran Model Kepemimpinan Di Era Society 5.0 Bagi Taruna Akademi Angkatan Udara
}

\author{
(Transformational Leadership is an Alternative Learning \\ Leadership Model in the Era of Society 5.0 for \\ The Indonesian Air Force Academy Cadets)
}

\author{
An Naas Falaq Maharta ${ }^{1 *}$, Dody Sumardi ${ }^{2}$ \\ 1,2 Prodi Teknik Manajemen Industri Pertahanan, Akademi Angkatan Udara, Yogyakarta \\ E-mail: annasfalaq33@gmail.com,dodysumardi94@aau.ac.id
}

\begin{abstract}
The era of Society 5.0 which is a concept where the development of the Internet of Things, Big data, and Artificial Intelligence is oriented to a better human life, in contrast to the concept in the Industrial Revolution 4.0 where the technology developed is oriented towards the productivity of business processes, this has changed the order of life. . Transformational leadership as an alternative leadership style that can adapt to the future with the development of the era of society 5.0 and face the critical millennial generation who are trained to cadets at the Indonesian Air Force Academy. The writing of this manuscript uses a descriptive analysis method that examines the literature with the opinions of experts and several previous studies. Based on research by Megawati et al, transformational leadership has a positive and significant effect on job performance as evidenced by the results of simple regression calculations or the results of the t-test, the t-count value is 9.451 while the t-table value is 2.024. This means that the value of $t$ count $>t$ table and obtains the highest significance value of 0.00 .
\end{abstract}

Keywords— Era Society 5.0, Leadership, Achievement

Abstrak- Era Society 5.0 yang merupakan sebuah konsep dimana pengembangan Internet of Things, Big data, dan Artifical Intelligence diorientasikan untuk kehidupan manusia yang lebih baik, berbeda dengan konsep di Revolusi industri 4.0 dimana teknologi yang dikembangkan berorientasi pada produktifitas proses bisnis, hal ini telah merubah tatanan kehidupan. Kepemimpinan transformasional sebagai alternatif gaya kepemimpinan yang dapat menyesuaikan masa depan dengan perkembangan era society 5.0 dan menghadapi generasi milineal yang kritis yang dilatihkan kepada Taruna di Akademi Angkatan Udara. Penulisan naskah ini menggunakan metoda analisis deskriptif yang mengkaji pustaka dengan pendapat dari para ahli dan beberapa penelitian terdahulu. Berdasarkan penelitian Megawati dkk kepemimpinan transformasional berpengaruh positif dan signifikan terhadap pretasi kerja dengan dibuktikan dengan hasil perhitungan regresi sederhana atau hasil uji $t$ diperoleh nilai $t$ hitung adalah 9,451 sedangkan nilai t tabel 2,024. Artinya nilai $t$ hitung > t tabel dan memperoleh nilai signifikansi tertinggi yaitu 0,00 .

Kata Kunci- Era Society 5.0, Kepemimpinan, Prestasi,

\footnotetext{
*Penulis Korespondensi (An Naas Falaq Mahartas)
}

E-mail: annasfalaq33@gmail.com 


\section{Pendahuluan}

$\mathrm{K}$ epemimpinan pada hakekatnya adalah sesuatu yang melekat pada diri seorang pemimpin yang berupa sifat-sifat tertentu seperti: kepribadian (personality), kemampuan (ability) dan kesanggupan (capability). Kepemimpinan juga sebagai rangkaian kegiatan (activity) pemimpin yang tidak dapat dipisahkan dengan kedudukan (posisi) serta gaya atau perilaku pemimpin itu sendiri, kepemimpinan adalah proses antara hubungan atau interaksi antara pemimpin, pengikut, dan situasi[1]. Kepemimpinan transformasional adalah kepemimpinan seorang pemimpin dalam bekerja dengan/dan/atau melalui orang lain untuk mentransformasikan secara optimal sumber daya organisasi dalam rangka mencapai tujuan yang bermakna sesuai dengan target yang telah ditetapkan [2]. Akademi Angkatan Udara melatih dan mendidik Taruna untuk menjadi calon pimpinan TNI Angkatan Udara di masa mendatang dengan membentuk suatu organisasi di lingkungan Wing Taruna yang dinamakan Wingkorps Taruna.

Organisasi Taruna ini dibentuk agar Taruna memiliki jiwa kepemimpinan, kepribadian, kesanggupan menjalankan tugas dengan ikhlas, dan kemampuan yang maksimal untuk memimpin TNI Angkatan Udara dimasa mendatang, untuk itu guna melatih Taruna dibidang kepemimpinan yang dikehendaki mampu menjadi pemimpin masa depan maka dibentuk organisasi Wing Korps Taruna. Keorganisasian Wing Korps Taruna dipilih dari Taruna tingkat III menjelang menjadi tingkat IV yang memiliki kemampuan akademis dan kepribadian diatas rata-rata Taruna lainnya. Wing Korps Taruna dipimpin oleh seorang Komandan yang disebut Komandan Wing Korps Taruna atau disingkat Danwingkorpstar. Kepemimpinan Wingkorps Taruna disamping dapat mengendalikan kegiatan kehidupan Taruna juga mampu memberikan motivasi kepada Taruna untuk mencapai hasil pendidikan yang baik.

Istilah kepemimpinan transformasional bukanlah hal baru, istilah ini diciptakan oleh James MacGregor Burns pada tahun 1978. Kepemimpinan transformasional atau transformasional leadership adalah sebuah gaya kepemimpinan yang mengidentifikasi perubahan yang diperlukan, menyusun visi yang akan membuka jalan bagi perubahan yang dibuat dan melaksanakan rencana yang diperlukan agar perubahan tersebut terjadi. Adapun ciri-ciri dari kepemimpinan transformasional adalah : kharismatik, motivasi inspiratif, stimulasi intelektual dan perhatian secara individual. Sesuai dengan ciri-ciri kepemimpinan transformasional, Kelompok Komando (Pokdo) Korps Taruna manerapkan metode kepemimpinan transformasional yang dapat dilihat dari cara mereka memimpin. Kharismatik ini dilihat dari Pokdo Korps dapat mempengaruhi Taruna untuk selalu mendukung program kerja. Motivasi inspiratif ini dapat dilihat dari Pokdo Korps Taruna selalu sebisa mungkin melakukan komunikasi kepada Taruna untuk memberikan motivasi yang dapat meningkatkan semangat para Taruna dalam menjalankan pendidikannya di Akademi Angkatan Udara. Stimulasi Intelektual ini dapat dilihat dari kemampuan Pokdo Koprs Taruna untuk membantu memecahkan dan memberikan solusi yang tepat untuk menyelesaikan masalah yang dihadapi oleh Taruna. Perhatian secara individual ini dapat dilihat dari Pokdo Korps Taruna selalu memperhatikan Taruna yang dipimpinnya selalu memberikan nasihat-nasihat yang baik guna menjadi Taruna yang selalu berada pada jalurnya.

Diharapkan model kepemimpinan transformasional yang diterapkan oleh Pokdo Korps Taruna dapat mampengaruhi dan meningkatkan prestasi belajar Taruna. Untuk itu penulis mencoba menganalisis model kepemimpinan Pokdo Korps Taruna dalam menjalankan kepemimpinanya dan model kepemimpinannya dapat mempengaruhi terhadap prestasi taruna Akademi Angkatan Udara lebih baik dengan harapan model kepemimpinan ini dapat diterapkan di satuan nantinya. 


\section{LANDASAN TEORI}

Dalam penulisan ini menggunakan beberapa landasan teori yang dikemukakan oleh para ahli tentang pemimpin, kepemimpinan, kepemimpinan transformasional, prestasi dan prestasi belajar. Landasan teori tersebut adalah sebagai berikut:

\section{A. Pemimpin}

Pemimpin adalah anggota kelompok yang memiliki pengaruh terbesar pada kegiatan atau aktivitas kelompok dan memainkan peran yang sangat penting dalam mengarahkan tugas-tugas kelompok guna mencapai tujuan kelompok. [3] menyampaikan bahwa seorang pemimpin adalah seorang yang karena kecakapan pribadinya dengan atau tanpa pengangkatan resmi dapat mempengaruhi kelompok yang dipimpinannya untuk mengarahkan usaha kerjasama kearah pencapaian sasaran tertentu.

\section{B. Kepemimpinan}

Kepemimpinan adalah suatu bentuk persuasi, suatu seni menggerakan dan pembinaan kelompok orang-orang tertentu, biasanya melalui human relation dan motivasi yang tepat, sehingga tanpa adanya rasa takut mereka mau bekerja sama dan memahami untuk mencapai segala apa yang menjadi tujuan organisai. Kepemimpinan adalah proses oleh seseorang atau kelompok mencoba untuk mempengaruhi tugas-tugas dan sikap orang lain terhadap sebuah akhir dari hasil yang dikehendaki untuk mencapai visi misi organisasi [4].

\section{Kepemimpinan Transformasional}

Menurut Ardiansyah [2] kepemimpinan transformasional adalah kemampuan seseorang pemimpin dalam bekerja dengan dan/atau melalui orang lain untuk mentransformasikan, secara optimal sumber daya organisai dalam rangka mencapai tujuan yang bermakna sesuai dengan target capaian yang telah ditetapkan.

\section{Prestasi}

Prestasi berasal dari bahasa Belanda yaitu prestatie, yang berarti hasil dari usaha. Prestasi diperoleh dari usaha yang telah dilakukan oleh individu maupun kelompok. Prestasi dapat dicapai dengan mengandalkan kemampuan intelektual, emosional, dan spiritual, serta ketahanan diri dalam menghadapi situasi di semua aspek kehidupan. Menurut Surya dalam [5] prestasi adalah hasil dari pembelajaran atau perubahan perilaku yang melibatkan sains, keterampilan, dan sikap setelah proses tertentu, sebagai hasil dari pengalaman individu dalam berinteraksi dengan lingkungannya

\section{MetodoloGi}

Metodologi yang digunakan pada penulisan naskah ini adalah Metode analitis deskriptif dengan mengkaji dari literasi pustaka para ahli dan penelitian yang terkait dengan objek yang diteliti kemudian memaparkan hasil kajian tanpa analisis dan kesimpulan. Metode deskriptif analitis menurut [6] adalah suatu metode yang berfungsi untuk mendeskripsikan atau memberi gambaran terhadap objek yang diteliti melalui data atau sampel yang telah terkumpul sebagaimana adanya tanpa melakukan analisis dan membuat kesimpulan yang berlaku untuk umum. Objek yang diteliti adalah proses pendidikan Taruna AAU dalam memberikan pengalaman memimpin dan dipimpin untuk pembekalan nantinya saat disatuan. Objek

Kepemimpinan Transformasional Suatu Alternatif Pembelajaran Model Kepemimpinan Di Era Society 5.0 Bagi Taruna Akademi Angkatan Udara (An Naas Falaq Mahartas) 
penelitian menurut [6] dinamakan situasi sosial, yang terdiri atas tiga komponen yaitu place atau tempat dimana interaksi dalam situasi sosial sedang berlangsung, actor atau pelaku/orang-orang yang sedang memainkan peran tertentu, dan activity atau kegiatan yang dilakukan oleh aktor dalam situasi sosial yang sedang berlangsung.

\section{Pembahasan}

Perkembangan teknologi saat ini sangat pesat, selama ini dan sampai sekarang kita mengalami era revolusi industri 4.0 yang penuh gejolak disrupsinya yang menyebabkan ketidakpastian yang kompleks dan ambigu, dikhawatirkan invansi tersebut dapat menggerus nilai-nilai karakter kemanusiaan yang dipertahankan selama ini. Diawal tahun 2019 pemerintah Jepang mengeluarkan gagasan tentang Society 5.0, yang merupakan sebuah konsep dimana pengembangan Internet of Things, Big data, dan Artifical Intelligence diorientasikan untuk kehidupan manusia yang lebih baik, berbeda dengan konsep di Revolusi industri 4.0 dimana teknologi yang dikembangkan berorientasi pada produktifitas proses bisnis.

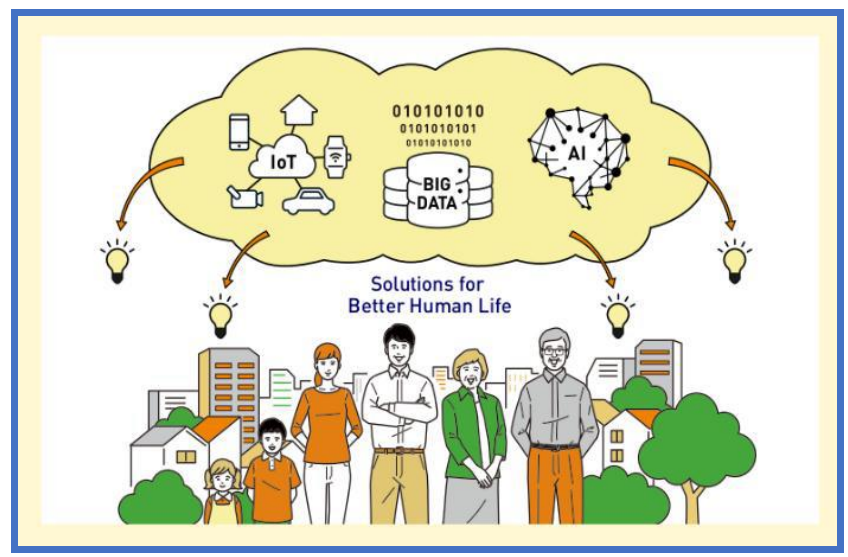

Gambar 1. Ilustrasi konsep society 5.0

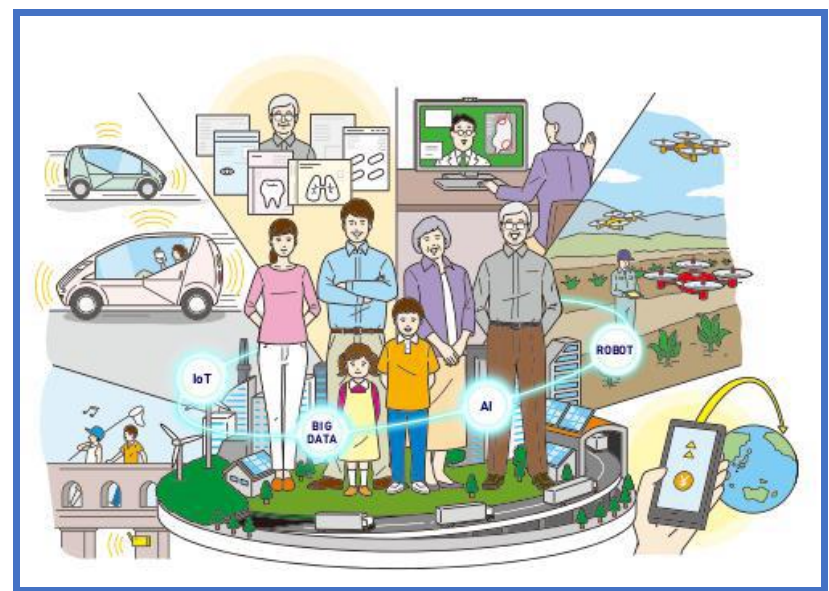

Gambar 2. Ilustrasi implementasi society 5.0

Society 5.0 menawarkan masyarakat yang berpusat pada manusia yang membuat seimbang antara kemajuan ekonomi dengan penyelesaian masalah sosial melalui sistem yang sangat 
menghubungkan melalui dunia maya dan dunia nyata. Guna menghadapi era society 5.0 perlu adanya peningkatan kualitas sumber daya manusia (SDM) agar implementasi perubahan konsep ini dapat dijalankan dengan baik. Lembaga pendidikan harus merubah paradigma pendidikan, pendidik menjadi penginspirasi bagi tumbuhnya kreativitas peserta didik. Pendidik berperan sebagai fasilitator, tutor, penginspirasi dan pembelajar sejati yang memotivasi peserta didik. revolusi society 5.0 ini lebih difokuskan pada manusia yang memiliki paradigma cara berpikir yang lebih kritis [7][8].

Perubahan paradigma di lembaga pendidikan harus secara serius dilakukan apalagi saat ini kita berhadapan dengan generasi milineal sebagai modal utama dalam fenomena bonus demografi yang memiliki potensi dapat dimaksimalkan akan mampu meningkatkan kemajuan disegala bidang. Selain itu, peran generasi milenial yang merata tanpa adanya kesenjangan gender juga akan mengoptimalkan manfaat dan potensi yang ada [9]. Generasi milineal merupakan generasi yang dilahirkan pada kurun waktu antara 1981 sampai dengan 2000an. Seperti yang disampaikan oleh Megawati, dkk. [10] Generasi milenial adalah sekelompok individu yang dilahirkan dalam definisi yang sama jangka waktu dan kata milenium didefinisikan sebagai kelompok orang yang lahir antara 1981 dan 2000 .

Berdasarkan literatur dari artikel Hitss.com, diketahui ada beberapa macam karakteristik dari generasi milenial yaitu: 1) milenial lebih percaya user generated content (UGC) daripada informasi searah, 2) milenial lebih memilih ponsel dibanding TV, 3) milenial wajib punya media sosial, 4) milenial kurang suka membaca secara konvensional, 5) milenial cenderung tidak loyal namun bekerja efektif, 6) milenial cenderung melakukan transaksi secara cashless, 7) milenial lebih tahu teknologi dibanding orang tua mereka, 8) milenial memanfaatkan teknologi dan informasi, 9) milenial cenderung lebih malas dan konsumtif, dan lain-lain [11]

Generasi Millenial secara karakteristik diidentifikasi sebagai ahli teknis dalam penggunaan teknologi mereka dan lebih cenderung menggunakan alat online secara luas dalam kehidupan sehari-hari mereka Banyak generasi milenium ingin bekerja untuk perusahaan yang mengembangkan pemikiran inovatif atau kreatif sehingga mereka dapat mengembangkan kompetensi dan berkontribusi positif untuk organisasi tersebut. Banyak cendekiawan inovasi lainnya mengakui generasi milenium sebagai orang yang percaya diri secara teknologi dan individu yang kompeten dengan rasa percaya diri yang kuat baik di dalam maupun di luar tempat kerja [12].

Prawirosentono [13] defenisi prestasi yakni hasil yang diperoleh secara maksimal setelah melalui sebuah proses usaha dan kerja keras tidak luput seperti belajar itu sendiri dan mencapai target sesuai keinginan. Prestasi dapat juga dikatakan sebagai suatu bukti dalam bentuk hasil akan kegiatan atau aktivitas yang dilakukan secara sungguh-sungguh. Menurut Priansa [14] faktor internal dan faktor eksternal merupakan dua faktor yang perlu diketahui. Faktor internal merupakan segala bentuk yang datang dari diri siswa, lain halnya dangan faktor eksternal dimana dipengaruhi oleh faktor dari luar diri siswa. Faktor internal terdiri atas kematangan fisik dan mental, pengetahuan, kecerdasan, serta keterampilan, minat dan motivasi serta faktor karakteristik pribadi lainnya. Sedangkan faktor eksternal meliputi keadaan guru, sarana, prasarana dan lingkungan sekitar seperti teman sebaya dan lain-lain. Prestasi dapat dipengaruhi oleh pihak luar yang dapat mengarahkan sehingga dapat tercapai prestasi yang maksimal. Robbins, dkk. [15] menjelaskan bahwa faktor eksternal berupa lingkungan sosial atau masyarakat sangat dominan mempengaruhi kegiatan belajar yakni orang tua yang dalam hal ini bapak dan ibu serta seluruh orang yang ada dalam keluarga.

Puspita, dkk. [16] menjelaskan bahwa prestasi belajar adalah proses perubahan akan perilaku seseorang atau individu, terhadap tatanan etika dan perilaku hidup yang baru, fungsional, disadari, positf akan terjadipeningkatan. Selanjutnya Syah [17] menjelaskan yakni prestasi belajar merupakan hasil belajar yang telah diperoleh oleh peserta didik atau siswa yang diperoleh dari hasil evaluasi atau diukur melalui proses penilaian. Indikator daripada prestasi belajar itu sendiri ditunjukkan dengan perubahan tingkah laku yang terdiri atas pengetahuan, sikap, serta keterampilan. 
Menghadapi generasi mileneal yang penuh dengan perkembangan teknologi informatika di revolusi society 5.0 yang lebih difokuskan pada manusia yang memiliki paradigma cara berpikir yang lebih kritis maka perlu seorang pemimpin yang mampu mengakomodir perkembangan terkini dan mengarahkan sesuai dengan tujuan organisasi. [18] mengutarakan bahwa pemimpin adalah seseorang yang mempergunakan wewenang kepemimpinannya untuk mengarahkan orang lain serta bertanggung jawab atas pekerjaan orang tersebut dalam mencapai suatu tujuan. Oleh karena itu diperlukan seorang pemimpin yang mampu memberikan arahan guna mencapai tujuan organisasi yang sudah ditetapkan. Jiwa kepemimpinan dalam memimpin merupakan tonggak utama sebuah perusahaan untuk termotivasi bekerja maksimal dan mampu bersaing dengan perusahaan yang lainnya [19].

Salah satu pendekatan yang dapat digunakan untuk mengetahui kesuksesan pemimpin ialah dengan mempelajari gayanya, karena gaya kepemimpinan banyak mempengaruhi keberhasilan seorang pemimpin dalam mempengaruhi perilaku bawahannya. [20] Dalam ilmu kepemimpinan saat ini, ada beberapa gaya kepemimpinan yang dikenal secara umum, yaitu (1) Gaya Diktatorial yaitu berwenang penuh dan memikul tanggung jawab sepenuhnya, (2) Gaya Militeristis yaitu pemberian perintah dalam menggerakan bawahannya (3) Gaya Paternalistik yaitu pemimpin diharapkan menjadi bapak bagi para pengikutnya, (4) Gaya Partisipatif yaitu pemimpin yang mendesentralisasi wewenangnya, (5) Gaya Laissez Faire yaitu gaya kemepimpinan yang memberi kebebasan penuh untuk membuat keputusan, (6) Gaya Bebas Kendali yaitu pemimpin yang menghindari kuasa dan tanggung jawab, (7) Gaya Karismatis pemimpin yang memiliki daya tarik yang tinggi, (8) Gaya Demokratis yaitu pemimpin yang cenderung melibatkan karyawan dalam mengambil keputusan [21].

Gary [22] menyatakan bahwa, "Kepemimpinan transformasional sebagai pemimpin yang menginspirasi para pengikutnya untuk melampaui kepentingan pribadi mereka yang mampu membawa dampak mendalam dan luar biasa pada para pengikut". Bass dan Avolio dalam Yukl [22] mengemukakan bahwa kepemimpinan transformasional mempunyai empat dimensi, yaitu:

Kharismatik (Charismatic) membuat perilaku pemimpin yang dapat membuat para anggotanya bisa mengagumi, menghormati, dan sekaligus mempercayainya. Meyakinkan kepada anggota tentang rencana dan tujuan yang dibuat oleh pemimpin dalam organisasi, sehingga dalam mengarahkan anggotanya akan dapat lebih ditaati atau diikuti petunjuk dan instruksinya.

Motivasi yang Menginspirasi (Inspirational Motivation) merupakan pemimpin yang mampu mengartikulasikan pengharapan yang jelas terhadap prestasi bawahan, mendemonstrasikan komitmennya terhadap seluruh tujuan organisasi, dan mampu menggugah spirit tim dalam organisasi melalui penumbuhan antusiasme dan optimisme, sehingga anggotanya akan sangat termotivasi tanpa beban untuk melaksanakan tugasnya dengan baik.

Stimulasi Intelektual (Intellectual stimulation) merupakan perilaku pemimpin yang mampu menumbuhkan ide ide baru, memberikan solusi yang kreatif terhadap permasalahanpermasalahan yang dihadapi bawahan, dan memberikan peluang kepada bawahan untuk mencari pendekatan-pendekatan yang baru dalam melaksanakan tugas-tugas organisasi.

Perhatian secara Individual (Individualized consideration) merupakan perilaku seorang pemimpin yang mau mendengarkan dengan penuh perhatian masukan-masukan anggotanya dan secara khusus mau memperhatikan kebutuhan-kebutuhan bawahan akan pengembangan karir anggotanya. 
TABEL I

TABEL UJI SIGNIFIKANSI PARSIAL (UJI STATISTIK T)

\section{Coefficients $^{\mathbf{a}}$}

\begin{tabular}{|c|c|c|c|c|c|c|}
\hline \multicolumn{2}{|c|}{ Model } & \multicolumn{2}{|c|}{$\begin{array}{l}\text { Unstandardized } \\
\text { Coefficients }\end{array}$} & \multirow{2}{*}{$\begin{array}{c}\text { Standardized } \\
\text { Coefficients } \\
\text { Beta }\end{array}$} & \multirow[t]{2}{*}{$\mathrm{T}$} & \multirow[t]{2}{*}{ Sig. } \\
\hline & & B & Std. Error & & & \\
\hline \multirow[t]{2}{*}{1} & (Constant) & 3.101 & 1.506 & & 2.059 & .046 \\
\hline & $\mathrm{X}$ & .425 & .045 & .838 & 9.451 & .000 \\
\hline
\end{tabular}

a.Dependent Variable: Prestasi kerja pegawai (Y)

Sumber : output SPSS 24.00

Pengaruh kepemimpinan tranformasional terhadap prestasi kerja pernah dilakukan penelitian oleh Megawati, dkk. [9] dan mendapatkan kesimpulan bahwa gaya kepemimpinan transformasional berpengaruh positif dan signifikan terhadap pretasi kerja pegawai pada kantor bupati kabupaten Majene. Hal ini dibuktikan dengan hasil perhitungan regresi sederhana atau hasil uji t diperoleh nilai thitung adalah 9,451 sedangkan nilai ttabel 2,024. Artinya nilai thitung $>\mathrm{t}$ tabel dan memperoleh nilai signifikansi tertinggi yaitu 0,00 .

Berdasarkan uraian diatas dapat disimpulkan bahwa kepemimpinan Tranformasional dapat menjadi alternatif gaya kepemimpinan yang beranggotakan generasi milinel diera Society 5.0 yang memiliki daya pikir kreatif yang penuh dengan teknologi informasi terkini. Gaya kepemimpinan tranformasional ini dapat dilatihkan atau dipraktekan pada proses pendidikan Taruna Akademi Angkatan Udara dengan alasan:

Taruna saat ini merupakan generasi milinel yang lahir sekitar tahun 1980 sampai dengan 2000an yang mampu menggunakan teknologi informasi lebih dari generasi lebih tua dari generasi mileneal. Anggota yang akan dipimpin saat penugasan nanti juga masih termasuk generasi milinel, minimal generasi yang lahir mendekati tahun 1980an sehingga perlu memimpin dengan gaya kepemimpinan yang sama dengan generasinya.

Dalam proses pendidikan di AAU saat ini sudah banyak menggunakan teknologi informasi, minimal terpengaruh oleh dunia luar yang menggunakan konsep era society 5.0 untuk dapat tetap mengikuti perkembangan jaman yang lebih maju. Setiap pengikut atau orang yang dipimpin, termasuk taruna mengharapkan pemimpin kharismatik, yang dapat memberikan perhatian secara intens, mampu memotivasi dan dapat menstimulus dalam mencapai tujuan organisasi tanpa merasa terbebani.Pengalaman kepemimpinan dengan gaya kepemimpinan transformasional dapat diberikan kepada kepada Taruna AAU dalam bentuk organisasi yang saat ini berlaku yaitu Wing Korps Taruna dengan memberikan pengetahuan yang meliputi dimensi kharisma, motivasi yang menginspirasi, stimulasi intelektual dan perhatian secara individual. Diharapkan pengalaman kepemimpinan tranformasional yang diberikan kepada Taruna juga dapat meningkatkan prestasi Taruna lainnya, sehingga pencapaian Taruna gemilang dapat terlaksana dengan baik.

\section{KESIMPULAN}

Kesimpulan dari naskah diatas adalah terdapat kelebihan yang dimiliki pada kepemimpinan Tranformasional yang mampu meningkatkan prestasi kerja anggotanya untuk mencapai tujuan yang diharapkan. Sistem pendekatan persuasif, mengerti apa yang dibutuhkan anggota dan tanpa ada kekerasan, kepemimpinan transformasional dapat sebagai alternatif pengembangan dan pelatihan bagi Taruna Akademi Angkatan Udara dalam wadah organisasi Wing Korps Taruna AAU yang akan dapat memberikan pengalaman kepemimpinan bagi Taruna disatuan nantinya. Kepemimpinan transformasional yang memiliki dimensi kharismatik, menumbuhkan motivasi yang dapat menginspirasi, memberikan stimulasi intelektual dan memberikan perhatian individual kepada Taruna. 


\section{UCAPAN TERIMA KASIH}

Ucapan terima kasih atas terbitnya naskah ini pada Seminar Nasional Sains Teknologi dan Inovasi Indonesia 2021 Akademi Angkatan Udara. Gubernur AAU Marsekal Muda TNI Nanang Santoso, Dosen Pembimbing Kolonel Adm Dody Sumardi

\section{REFERENSI}

[1] "WAHJOSUMIDJO. 1987. KEPEMIMPINAN DAN MOTIVASI. JAKARTA: GHALIA INDONESIA.”.

[2] "Ardiansyah, B. (2010). Berprestasi Tujuan Hidupku. Bali: Departemen Pendidikan Nasional Provinsi Bali”.

[3] "Ariwaseso, Galih. 2012. Minat Dan Kebiasaan Belajar Terhadap Prestasi Belajar Mata Pelajaran Akuntansi Siswa Kelas Xi Ips Sma Negeri 1 Pataianrowo Nganjuk. Fakultas Ekonomi: Universitas Negeri Surabaya".

[4] S. Rahma, G. A. Suhandana, and N. K. Suarni, "Danim, Sudarwan. 2004. Kepemimpinan Pendidikan. Bandung: CV Alfabeta," vol. 4, p. 12, 2013.

[5] "Fiedler, Fred E. A Theory of Leardership Effectiveness. New York: McGrawHill, 1967".

[6] "Hasibuan, Malayu. 2001. Manajemen Sumber Daya Manusia. Jakarta: Bumi Aksara".

[7] "Hidayatullah, Abdul Waris, Riezky Chris Devianti, 2018, Perilaku Generasi Milenial dalam Menggunakan Aplikasi Go-Food Syarif pemimpinan dan Motivasi. Jakarta: Ghalia Indonesia".

[8] E. W. Megow, R. W. . Triputro, and Ardian Infantono, "MEMBANGUN KEPEMIMPINAN KUAT DAN TANGGUH PADA PENGEMBANGAN SUMBER DAYA APARATUR PEMERINTAH DAERAH MELALUI PENDIDIKAN DAN PELATIHAN", EMBISS, vol. 1, no. 3, pp. 219-229, May 2021.

[9] "Kurniawan, Hendra. 2011. Pengaruh Gaya Kepemimpinan Transformasional Terhadap Kinerja Karyawan PT. Berau Karya Indah Di Surabaya Melalui Motivasi Kerja. Skripsi Tidak Diterbitkan. Surabaya: Fakultas Ekonomi Dan Bisnis Universitas Airlangga Surabaya".

[10] "Megawati dkk, Pengaruh Gaya Kepemimpinan Transformasional Terhadap Prestasi Kerja Pegawai Pada Kantor Bupati Kabupaten Majene, Jurnal Ilmu Manajemen Profitability Vol 1, No 1 (2017): PROFITABILITY : JURNAL ILMU MANAJEMEN".

[11] "Moeheriono. 2012. Pengukuran Kinerja Berbasis Kompetensi. Jakarta: Raja Grafindo Persada".

[12] S. Hidayatullah, A. Waris, and R. C. Devianti, "Perilaku Generasi Milenial dalam Menggunakan Aplikasi GoFood," J. Manaj. DAN KEWIRAUSAHAAN, vol. 6, no. 2, p. 240, Dec. 2018, doi: 10.26905/jmdk.v6i2.2560.

[13] "Prawirosentono, Suryadi. 1999. Kebijakan Kinerja Karyawan. Yogyakarta: BPFE".

[14] "Priansa, D. J. (2015). Manajemen Peserta Didik dan Model Pembelajaran. Bandung: Alfabeta".

[15] "Robbins, P. Stephen dan Mary Coulter. 2010. Manajemen, diterjemahkan oleh Bob Sabran, Wibi Hardani. Erlangga:Jakarta".

[16] Y. Puspita, Y. Fitriani, S. Astuti, and S. Novianti, "SELAMAT TINGGAL REVOLUSI INDUSTRI 4.0, SELAMAT DATANG REVOLUSI INDUSTRI 5.0,” p. 9, 2020.

[17] "Slameto. (2010). Belajar \& Faktor-faktor yang Mempengaruhi. Jakarta: Pustaka Indonesia".

[18] "Sugiyono. 2010. Metode Penelitian Kuantitatif, Kualitatif, dan R\&D. Bandung: Alfa Beta".

[19] "Syah, M. (2012). Psikologi Belajar. Jakarta: Rajawali Pers".

[20] Tambunan, Toman Sony, SE.,M.Si. Pemimpin dan Kepemimpinan. Cetakan pertama. Yogyakarta. GRAHA ILMU. ISBN: 978-602-262-465-3.

[21] "Yeni P dkk , 2020, Selamat Tinggal Revolusi Industri 4.0, Selamat Datang Revolusi Industri 5.0, Prosiding Seminar Nasional Pendidikan Program Pascasarjana Universitas Pgri Palembang 10 Januari 2020".

[22] "Yukl Gary. (2010). Leadership in Organizations Seven Edition. Pearson". 